\title{
Analyses of different varieties of epidote
}

\section{Hermann}

To cite this article: M. Hermann (1848) Analyses of different varieties of epidote, Philosophical Magazine Series 3, 33:224, 483-486, DOI: 10.1080/14786444808646149

To link to this article: http://dx.doi.org/10.1080/14786444808646149

册 Published online: 30 Apr 2009.

Submit your article to this journal

Џ Article views: 5

Q View related articles $₫$ 


\section{Intelligence and Miscellaneous Articles.}

tion was set aside, and the gas disengaged from the apparatus was passed through a fresh solution, which became immediately turbid, and gave in a few minutes a very evident precipitate; when the apparatus was uncorked, $M$. Filhol was surprised on finding that the gas disengaged had the odour of hydrosulphuric acid : the operation was discontinued till the next morning, and the current of gas was then passed into a third solution of nitrate of silver, which became immediately turbid; in a few minutes nearly the whole of the silver was precipitated, the gas emitting a strong smell of hydrosulphuric acid.

The author states he always employed very dilute sulphuric acid, in order to avoid the production of hydrosulphuric acid pointed out by MM. Fordos and Gelis.

The black precipitates obtained, evidently contained sulphuret of silver, but it was possible that arseniuretted hydrogen might also be disengaged, independently of the hydrosulphuric acid; to ascertain this hydrochloric acid was added to each solution, the chloride of silver was separated by filtration, and the filtered liquids were treated with hydrosulphuric acid; in all of them a yellow precipitate was formed, which was found to be sulphuret of arsenic.

M. Filhol is of opinion that from these experiments he may conclude that the natural sulphurets of arsenic are not absolutely unacted upon in Marsh's apparatus, as hitherto supposed; that they are very slowly decomposed, and that the quantity of arsenic brought over by the hydrogen is too small to produce arsenical spots; that it requires a long time to ascertain its presence in the metallic solutions which have retained it; that nascent hydrogen acts on both elements of these sulphurets, and always contains traces of hydrosulphuric acid and arseniuretted hydrogen.

'The author observes that M. Chevallier's experiments on the natural sulphurets of arsenic are nowise in opposition to the preceding facts, since the washings of the sulphurets in the experiments of M. Chevallier contained traces of arsenious acid, which M. Filhol's did not; and he thinks the slowness of the action on the sulphurets of arsenic will account for their having been supposed to be not acted upon at all.

From the experiments detailed the author is of opinion, that though he has not succeeded in rigorously demonstrating the presence of arsenic in the cases alluded to, he has shown that it may exist in the state of sulphuret in the deposits of certain natural chalybeate waters, and that it ought to be searched for in those which contain sulphates; the same remark applies to the searches for arsenic in the earth of cemeteries.-Journ. de Chim. Méd., Octobre 1848.

\section{ANALYSES OF DIFFERENT VARIETIES OF EPIDOTE.}

BY M. HEIRMANN.

The author has subjected to analysis a great number of the varieties of epidote, such as zoisites, pistazites, orthites, \&c., found in part in the Ural.

Zoisites.-_Grey zoisite from Falltigel in the Tyrol; density, $\mathbf{3 \cdot 2 8}$. Imbedded in granite. 
Silica ............ 40.95

Alumina ............ $30^{\cdot 24}$

Lime ............ 21.56

Protoxide of iron. ...... 4.96

Carbonic acid ......... 1.13

Water............ 0.56

$99 \cdot 40$

This analysis agrees with the previous results of $M$. Geff ken from the zoisite of the same locality, and with those of other analysts from different places.

Green zoisite from Arendal; density, 3.17.

Silica ............. $37 \cdot 32$

Alumina ........... $22 \cdot 85$

Lime $\ldots \ldots \ldots \ldots \ldots 22 \cdot 03$

Magnesia.......... 0.77

Peroxide of iron $\ldots \ldots \ldots 11.56$

Protoxide of iron. ....... 1 186

Carbonic acid ......... 2.64

Water ............ $0 \cdot 29$

$\overline{99 \cdot 32}$

Green zoisite from Achmatowsk; density, $\mathbf{3} \cdot 33$.

Silica ............ $37 \cdot 32$

Alumina ............. $22 \cdot 85$

Lime ............. 22.03

Magnesia........... 0.77

Peroxide of iron ........ $11 \cdot 56$

Protoxide of iron....... 1.86

Carbonic acid .......... 2.64

Water ............ 0.56

$\overline{99 \cdot 59}$

Green zoisite from Schumnaja; density, 3.43.

Silica ............ $36 \cdot 45$

Alumina . . . . . . . . . 24.92

Lime . . ........... 22*45

Peroxide of iron ........ $9 \cdot 54$

Protoxide of iron........ $3 \cdot 25$

Carbonic acid ......... 2.73

Water ........... 0.77

$\overline{100 \cdot 11}$

Pistazite from Arendal, in large blackish-green crystals ; density, $3 \cdot 49$.

Silica $\ldots \ldots \ldots \ldots \ldots, 36 \cdot 79$

Alumina .......... $21 \cdot 24$

Lime .......... 21 27

Peroxide of iron ....... 12.96

Protoxide of iron...... $5 \cdot 20$

Carbonic acid ........ $2 \cdot 31$

Water............ 0.55 
The previous analyses of Rammelsberg, Geffken and Kühn, agree with the foregoing.

Pistazite from Burowa, south of Miask, imbedded in quartz; density, $3 \cdot 35$.

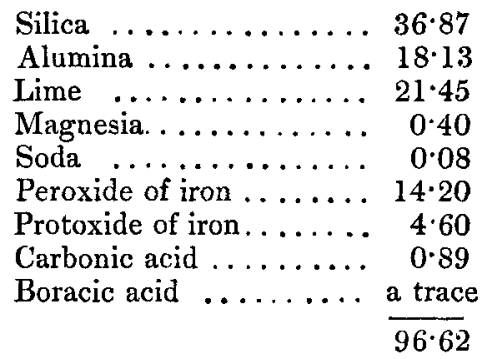

Pistazite from Werchneuvinsk, or puschkinite; density, 3.43 . The crystals are red or green, according to their position against the light.

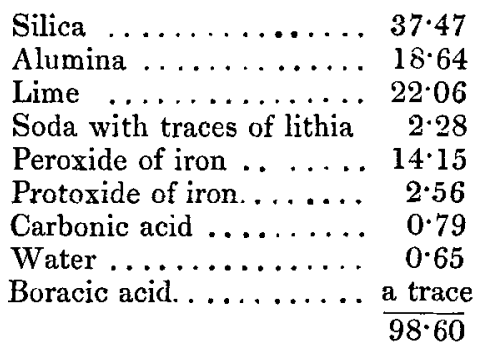

Pistazite from Bourg d'Oisans in Dauphiny, of an olive-green colour; density, $3 \cdot 38$.

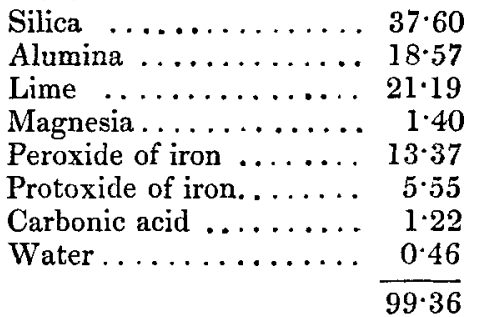

Pistazite from Achmatowsk, of a grass-green colour; density, 3.39 .

Silica ............ $37 \cdot 38$

Alumina . . . . . . . 18.25

Lime ........... 24.72

Magnesia. . . . . . . . . 0.39

Soda ............. 0.91

Peroxide of iron ....... 12.31

Protoxide of iron. . . . . . $2 \cdot 20$

Carbonic acid ........ 1.61

Water............. 0.59

Boracic acid ........ $\frac{\text { a trace }}{98 \cdot 36}$ 
Bucklandite. This mineral, considered hitherto as black sphene, is met with at Achmatowsk, in isolated crystals in calcareous spar, accompanied with garnet and diopside; density, 3.51. M. Auerbach determined the measures, which coincide perfectly with the form of other epidotes.

It yielded by M. Hermann's analysis,-

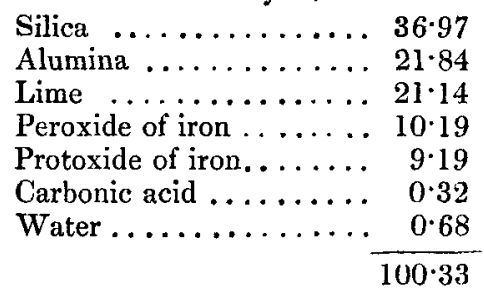

Orthite or ceriferous epidote. Tschewkinite is often confounded with the orthite of Miask, but the former is much the denser (4.50). Several trials gave M. Hermann numbers varying between $3 \cdot 4$ and 3.6 for the density of the orthite of Miask. By analysis orthite yielded-

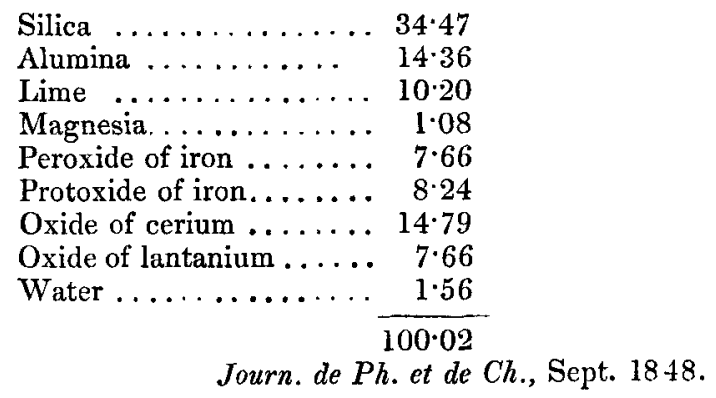

ON THE PREPARATION OF BLACK SULPHURET OF MERCURY.

M. C. Vogler remarks, that the usual method of preparing Ethiops' mineral consists in triturating pure metallic mercury with washed flowers of sulphur in a porcelain or marble mortar. The mixture is sprinkled occasionally either with water or spirit of wine, and the trituration is continued until globules of mercury are no longer discoverable by the glass. Such a process ought not, however, to be recommended; for when the mixture ceases to be moistened sufficiently, part of it rises in dust, which not only occasions loss of material, but exposes the operator to the inconvenience of respiring mercurial vapour.

To remedy these inconveniences the author proposes the following plan :-Take a thick glass vessel, capable of holding twelve to sixteen ounces, put into it four ounces of mercury and one ounce of finelypowdered flowers of sulphur; shake them continually for about two hours, then add another ounce of sulphur, removing the cork of the vessel occasionally; shake again until globules are no longer visible with the naked eye; lastly, add two more ounces of sulphur and 